\title{
Highly Norbornylated Cellulose and Its "Click" Modification by an Inverse-Electron Demand Diels-Alder (iEDDA) Reaction
}

\author{
Christina Wappl ${ }^{1}$, Viktor Schallert ${ }^{1}$, Christian Slugovc ${ }^{1}$, Astrid-Caroline Knall ${ }^{1, *}$ and Stefan Spirk ${ }^{2, *}$ (D) \\ 1 Institute for Chemistry and Technology of Materials, Graz University of Technology, Stremayrgasse 9, \\ 8010 Graz, Austria; christina.wappl@outlook.com (C.W.); viktor.schallert@tugraz.at (V.S.); \\ slugovc@tugraz.at (C.S.) \\ 2 Institute of Bioproducts and Paper Technology, Graz University of Technology, Inffeldgasse 23A, \\ 8010 Graz, Austria \\ * Correspondence: astrid.knall@gmail.com (A.-C.K.); stefan.spirk@tugraz.at (S.S.)
}

Citation: Wappl, C.; Schallert, V.; Slugovc, C.; Knall, A.-C.; Spirk, S. Highly Norbornylated Cellulose and Its "Click" Modification by an Inverse-Electron Demand Diels-Alder (iEDDA) Reaction. Molecules 2021, 26, 1358. https:// doi.org/10.3390/molecules26051358

Academic Editor: Pedro Fardim

Received: 29 January 2021

Accepted: 26 February 2021

Published: 4 March 2021

Publisher's Note: MDPI stays neutral with regard to jurisdictional claims in published maps and institutional affiliations.

Copyright: (c) 2021 by the authors. Licensee MDPI, Basel, Switzerland. This article is an open access article distributed under the terms and conditions of the Creative Commons Attribution (CC BY) license (https:/ / creativecommons.org/licenses/by/ $4.0 /)$.

\begin{abstract}
A facile, catalyst-free synthesis of a norbornylated cellulosic material (NC) with a high degree of substitution (2.9) is presented by direct reaction of trimethylsilyl cellulose with norbornene acid chloride. The resulting NC is highly soluble in organic solvents and its reactive double bonds were exploited for the copper-free inverse-electron demand Diels-Alder (iEDDA) "click" reaction with 3,6-di(pyridin-2-yl)-1,2,4,5-tetrazine. Reaction kinetics are comparable to the well-known Huisgen type 1,3-dipolar cycloaddition of azide with alkynes, while avoiding toxic catalysts.
\end{abstract}

Keywords: cellulose; click chemistry; iEDDA; copper-free; norbornene cellulose; cellulose ester

\section{Introduction}

In recent years, "click" chemistry entered into the focus of research in many disciplines, since it allows for a selective coupling of two or more moieties via dedicated functional groups [1,2]. An ideal "click" reaction leads to selective and fast conversion of the reaction partners, while being environmentally benign. In order to prevent undesired side reactions and by-products, the effort for working up the reaction product is minimized. A wellknown "click" reaction is the $\mathrm{Cu}(\mathrm{I})$-catalyzed Huisgen 1,3-dipolar cycloaddition of azides and terminal alkynes (CuAAC) to give 1,2,3-triazoles [1,3]. The popularity of the CuAAC originates from its robustness, tolerating a wide range of chemical conditions as well as good stereoselectivity. "Click" reactions as efficient method of linking two components have made their way into the polymer chemist's toolbox. Several examples have been also reported for cellulose, the most abundant biopolymer on earth [4-10]. For materials with an intended use in medicine, in some cases copper is a critical issue and strict regulations do exist due to known side effects on the human body upon excessive copper intake (e.g., liver damage [11], Alzheimer's disease [12]). As a consequence, intense efforts have been made to establish "click" chemistries which avoid copper catalysts. In this context, it should be mentioned that there are some examples where Huisgen type "click" reactions proceed without any copper catalyst even at room temperature (e.g., cycloadditions of cyclooctynes) albeit reaction kinetics are rather slow and regioselectivity is often not realized in a satisfactory manner [13].

Further copper-free approaches were presented by Bertozzi and Boons [13-17]. However, we became particularly interested in the Diels-Alder reaction with inverse-electron demand (iEDDA) due to the significantly increased reaction kinetics [18] and the possibility to combine iEDDA with other "click" reactions leading to orthogonally modifiable structures [19].

The use of iEDDA reactions between tetrazines and strained olefins and their application as a "click" reaction has not been exploited as extensively as CuAAC, in spite of many impressive applications having emerged recently [20]. Furthermore, the rate constants can be adjusted by selection of appropriate reaction partners, i.e., a less reactive olefin can 
be converted with a more reactive (more electron-deficient) tetrazine [13,21]. In terms of biocompatibility, tetrazines have been already used in a variety of "click" reactions for an intended use in medicine and a summary of biomedical applications can be found in a review $[22,23]$.

Here, we present a facile approach to "click" cellulose derivatives using an iEDDA reaction avoiding the use of copper. In particular, the reaction of a highly substituted norbornene cellulose ester with a tetrazine is investigated and analyzed using state of the art analytical techniques.

\section{Results and Discussion}

Due to the aforementioned good selectivity of iEDDA reactions and their biocompatibility, we were interested in whether we could transfer this concept to cellulose chemistry. To accomplish this target, we identified norbornenes as suitable reaction partners to be immobilized on the cellulose backbone since they are sufficiently reactive dienophiles for iEDDA reactions due to their strain-activated double bond while avoiding the problems typically associated with more reactive dienophiles like trans-cyclooctenes such as storage stability due to isomerization [24]. Another issue is that norbornenes are synthetically easy to access, bearing a variety of functional groups. Consequently, norbornene esters of cellulose were selected as test compounds (Figure 1).
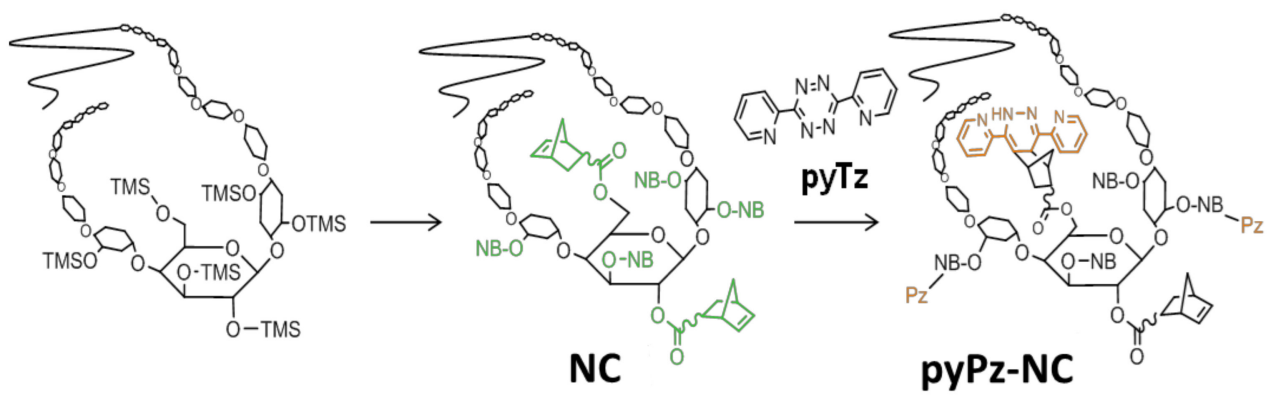

Figure 1. Norbornylation of cellulose and iEDDA reaction on norbornylated cellulose (NC) with 3,6di(pyridin-2-yl)-1,2,4,5-tetrazine (pyTz) leading to the formation of a dipyridinyl dihydropyridazine (pyPz)-functionalized NC.

The most convenient route to the desired norbornene cellulose esters proceeds via a catalyst free, direct desilylation-esterification of highly substituted commercially available trimethylsilyl cellulose (TMSC) with norbornoyl chloride in the presence of a base at slightly elevated temperatures $[25,26]$. Under the chosen reaction conditions, efficient substitution of silyl groups by ester bonds was accomplished as proven for derivatives having a degree of substitution $\left(\mathrm{DS}_{\mathrm{Si}}\right)$ of 2.8-2.9. Both the excess acid chloride as well as the exclusive by-product, trimethylsilyl chloride can be easily removed. The reaction gives 2,3,6-norbornoyl cellulose (NC) with a DS close to 3.0 after workup. Workup was performed using a mixture of THF and $0.1 \mathrm{M}$ aqueous $\mathrm{K}_{2} \mathrm{CO}_{3}$ to neutralize traces of nonreacted acid chloride followed by extraction of the NC with dichloromethane. Attempts to replace the THF in the workup by ecologically more favored methanol led to the formation of methyl-5-norbornene 2-carboxylate as side product which is very difficult to separate from the NC. The obtained NC exhibits good solubility in a wide range of organic solvents such as $\mathrm{CHCl}_{3}$, toluene, as well as diethyl ether and THF.

ATR-FTIR spectroscopy (Figure 2) clearly indicates the formation of the ester bond $\left({ }^{*}, v_{\mathrm{C}=\mathrm{O}}\right.$ at $\left.1736 \mathrm{~cm}^{-1}\right)$ and the presence of norbornene $\mathrm{C}=\mathrm{C}$ fragments $\left({ }^{\wedge}, v_{\mathrm{C}=\mathrm{C}-\mathrm{H}}: 711 \mathrm{~cm}^{-1}\right.$, $v_{\mathrm{C}=\mathrm{C}}: 1571, v_{\mathrm{C}=\mathrm{C}-\mathrm{H}}: 3061 \mathrm{~cm}^{-1}$ ) concomitant with the disappearance of bands assigned to $v_{\mathrm{Si}-\mathrm{C}}\left({ }^{\prime}, 1250 \mathrm{~cm}^{-1}\right)$ and $\delta_{\mathrm{Si}-\mathrm{O}-\mathrm{C}}\left({ }^{\circ}, 833,746 \mathrm{~cm}^{-1}\right)$. 


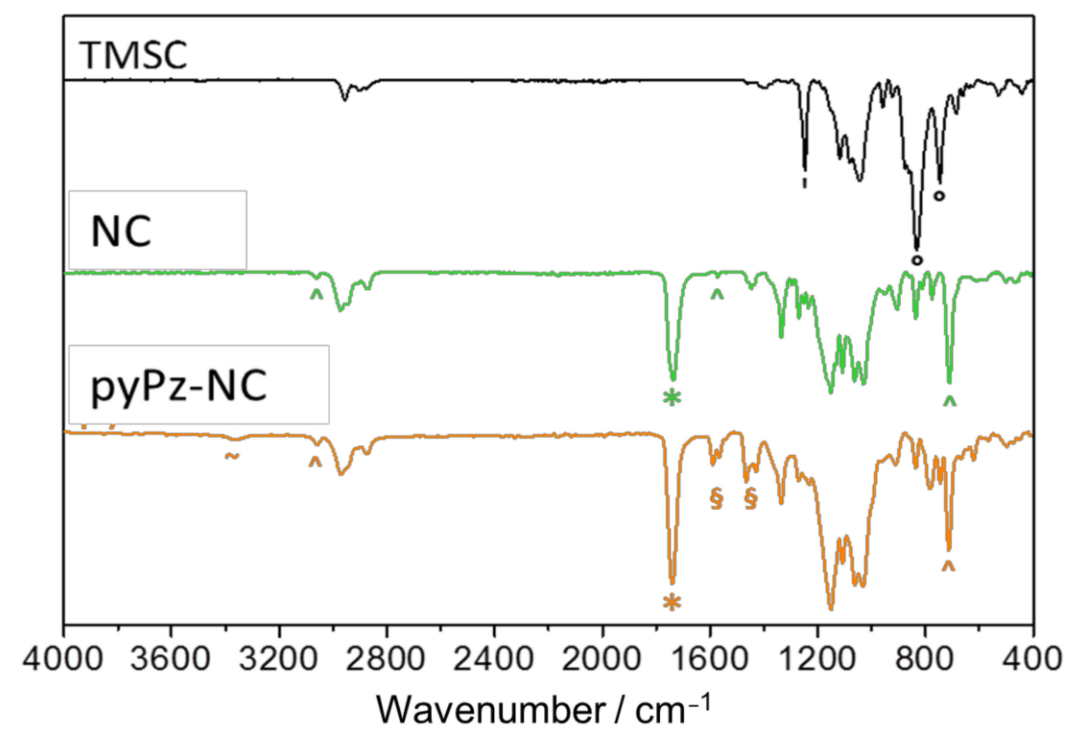

Figure 2. Comparison of the ATR-IR spectra of TMSC, NC and the pyPz-NC. Characteristic bands: ${ }^{\circ}=$ TMS groups, ${ }^{\wedge}=$ norbornene double bonds $*$ = carbonyl groups, $\sim$ = dihydropyridazine, $\S=$ pyridines. Please note that spectra are not normalized.

The presented DS of 2.85 is directly determined from the ${ }^{1} \mathrm{H}-\mathrm{NMR}$ spectrum (Figure 3 ). The integral value for the proton signals of the norbornene double bonds (N5 and N6, $6.43-5.55 \mathrm{pm})$ is related to the integral value of the pyranose ring (C1-C6, 5.27-3.33 ppm). The amount of remaining TMS groups is less than $0.5 \%$ as indicated by the small signal at $0.06 \mathrm{ppm}$.

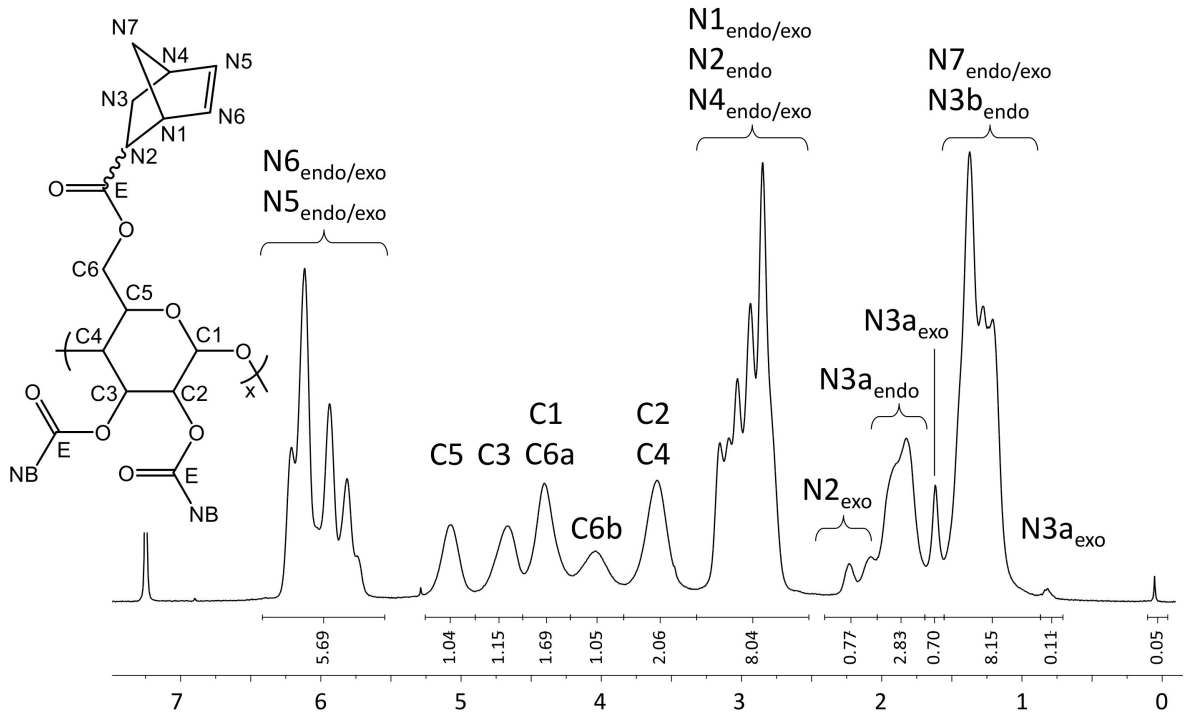

Figure 3. ${ }^{1} \mathrm{H}-\mathrm{NMR}$ spectrum of $\mathrm{NC}$ in $\mathrm{CDCl}_{3}$ at $298 \mathrm{~K}$.

These assignments are further supported by the ${ }^{13} \mathrm{C}$-NMR spectrum in $\mathrm{CDCl}_{3}$ (Figure 4). The $\mathrm{Si}\left(\mathrm{CH}_{3}\right)_{3}$ groups present in TMSC ( $\left.\delta: 0.0-1.5 \mathrm{ppm}\right)$ are below the detection limit of ${ }^{13} \mathrm{C}-\mathrm{NMR}$ after reaction with norbornene carboxylic acid chloride.

In turn, the typical shifts corresponding to an ester functionality ( $\delta: 172-176 \mathrm{ppm}$, endo- and exo-) as well as those corresponding to the norbornene alkenyl carbons ( $\delta$ : 132.5-138.5 ppm, endo- and exo-) are observed. There are only isolated signals for each $\mathrm{C}$-atom of the pyranose ring which are, in terms of pattern and chemical shifts, very similar to those reported for cellulose triacetate [27]. 


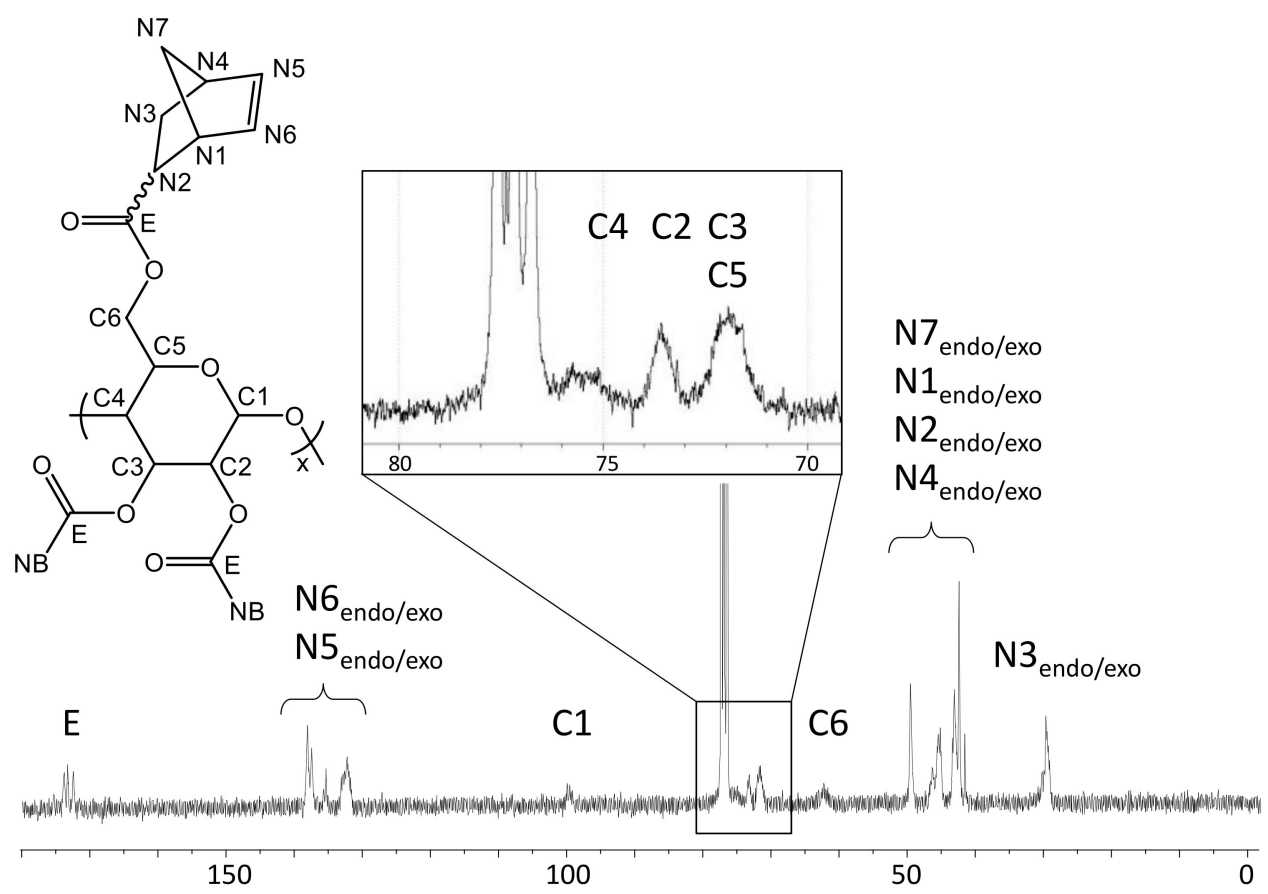

Figure 4. ${ }^{13} \mathrm{C}-\mathrm{NMR}$ spectrum of $\mathrm{NC}$ in $\mathrm{CDCl}_{3}$ at $298 \mathrm{~K}$.

After synthesis and characterization of the NC, the next step was to explore its capability to participate in an iEDDA reaction with pyTz. After addition of pyTz to NC in a molar ratio of 1:1 (corresponds to a ratio of 1 pyTz per 3 norbornene ester groups), the mixture was stirred overnight at room temperature. The color of the solution changed over this period from pink to yellow as the tetrazine is consumed and the dihydropyridazine (pyPz) moiety is formed (Figure 5). Precipitation of the concentrated solution gave a yellowish solid.

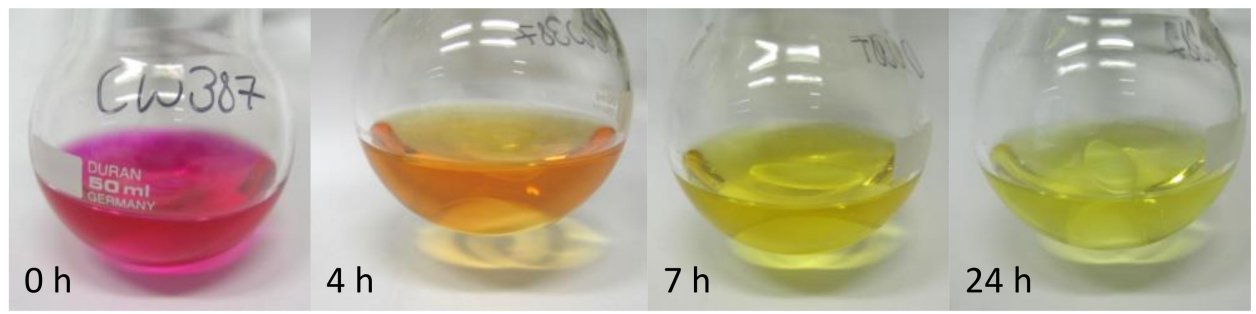

Figure 5. Change in color upon "click" reaction of NC with pyTz.

NMR spectroscopy of the pyPz-functionalized NC (pyPz-NC) was attempted, but excessive broadening of the signals hampered a detailed interpretation of the ${ }^{1} \mathrm{H}-\mathrm{NMR}$ spectrum but indicated the incorporation of the pyPz-moiety into the NC structure by the appearance of broad signals in the aromatic region (see Appendix A, Figure A4). However, the successful "click" immobilization of tetrazines onto NC can be clearly observed in the ATR-FTIR spectra (Figure 2). The new bands between 1400 and $1600 \mathrm{~cm}^{-1}$ (§) can be assigned to ring stretching vibrations of 2-monosubstituted pyridines. The signal for N-H stretching vibration at $3370 \mathrm{~cm}^{-1}(\sim)$ confirms the formation of the dihydropyridazine. The signals of the norbornene $C=C$ fragments $\left({ }^{\wedge}, v_{C=C-H}: 711 \mathrm{~cm}^{-1}, v_{C=C-H}: 3061 \mathrm{~cm}^{-1}\right)$ are still visible as statistically a maximum of only 1 out of 2.85 norbornene double bonds per anhydroglucose unit (AGU) are potentially converted.

The product was analyzed additionally by means of elemental analysis (CHN) to estimate the ratio of pyPz moieties on the NC-backbone. The results confirmed the successful "click" transformation introducing approximately 1 pyPz per AGU. 
The rate constant $k$ of the cycloaddition reaction of NC with pyTz was determined under pseudo first order conditions using UV-Vis spectroscopy. In order to evaluate the reactivity of NC towards pyTz, it was benchmarked with a small molecule, namely 5norbornene-2-carboxylic acid methyl ester (NM). The distinct absorption peak of the pyTz $\left(\lambda_{\max }=542 \mathrm{~nm}\right.$ in THF) allows for monitoring the progress of the "click" reaction by UV/VIS spectroscopy [28]. In order to ensure pseudo first order reaction conditions, an excess of the norbornene double bonds was accomplished (the norbornene double bond:pyTz ratio was 5:1, 10:1, 15:1) in those experiments (three parallels for each concentration). The pseudo first order reaction rate constants $k_{\text {app }}$ at different concentrations were obtained by linear fits of $\ln \left([\mathrm{pyTz}] /\left[\mathrm{pyTz}_{0}\right]\right)$ versus reaction time (Table 1$)$.

Table 1. Pseudo first order rate constants $k_{a p p}$ for iEDDA of pyTz with NC and NM.

\begin{tabular}{ccc}
\hline \multirow{2}{*}{ c(Alkene) (M) } & \multicolumn{2}{c}{ Pseudo First Order Rate Constant kapp $_{\text {ap }}$ (s) $^{-1}$ ) } \\
& NC & NM \\
\hline 0.005 & $6.55 \times 10^{-5} \pm 3.37 \times 10^{-6}$ & $1.02 \times 10^{-4} \pm 2.90 \times 10^{-6}$ \\
0.010 & $1.26 \times 10^{-4} \pm 3.96 \times 10^{-6}$ & $1.86 \times 10^{-4} \pm 4.83 \times 10^{-6}$ \\
0.015 & $1.79 \times 10^{-4} \pm 4.10 \times 10^{-6}$ & $2.77 \times 10^{-4} \pm 2.79 \times 10^{-6}$ \\
\hline
\end{tabular}

Figure 6 depicts the obtained, averaged $\mathrm{k}_{\mathrm{app}}$ rate constants at different double bond equivalents of NC and NM, respectively. By linear regression, a rate constant for the reaction of NC of $0.0114 \mathrm{~mol} \mathrm{~s}^{-1}$ was derived. This reaction rate only reduced by a factor of 1.5 compared to NM $\left(0.0175 \mathrm{~mol} \mathrm{~s}^{-1}\right)$ which highlights the applicability and versatility of iEDDA reactions particularly for polymeric supports.

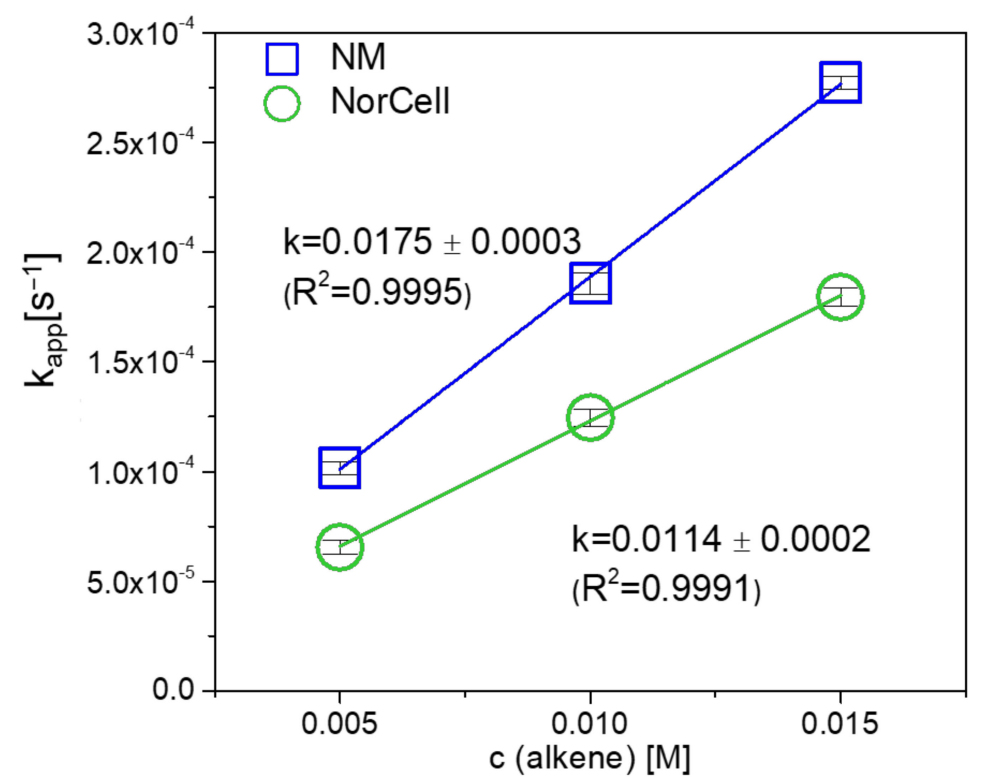

Figure 6. Reaction rates of NC and NM in iEDDA reaction with pyTz in THF under pseudo first order conditions.

\section{Materials and Methods}

\subsection{Materials}

Trimethylsilyl cellulose (TMSC, Avicel, $M_{\mathrm{W}}=185,000 \mathrm{~g} \cdot \mathrm{mol}^{-1}, M_{\mathrm{n}}=30,400 \mathrm{~g} \cdot \mathrm{mol}^{-1}$, $\mathrm{PDI}=6.1$ determined by GPC in chloroform) with a $\mathrm{DS}_{\mathrm{Si}}$ value of 2.8-2.9 was purchased from TITK (Rudolstadt, Germany). 5-norbornene-2-carboxylic acid chloride, methyl 5norbornene-2-carboxylate (NM) and 3,6-di(pyridin-2-yl)-1,2,4,5-tetrazine (pyTz) were prepared according to published literature procedures [29-31]. 


\subsection{Synthesis}

\subsubsection{Synthesis of 2,3,6-norbornoyl Cellulose (NC)}

TMSC (DS 2.8-2.9, $0.62 \mathrm{~g}, 1.67 \mathrm{mmol}$ ) was added to a mixture of freshly prepared 5-norbornene-2-carbonyl chloride $(4.5 \mathrm{~g}, 28.7 \mathrm{mmol})$ and 4-dimethylamino pyridine $(0.22 \mathrm{~g}$, $1.77 \mathrm{mmol}$ ) under an atmosphere of dry nitrogen. After stirring at $80^{\circ} \mathrm{C}$ overnight, $20 \mathrm{~mL}$ THF were added resulting in the precipitation of 4-dimethylaminopyridine hydrochloride which was removed by filtration. The filtrate was concentrated and added dropwise to an aqueous solution of $\mathrm{K}_{2} \mathrm{CO}_{3}(0.1 \mathrm{M})$ concomitant with the formation of a white solid. After addition of dichloromethane, the organic phase containing the $\mathrm{NC}$ was separated, washed again with aqueous $\mathrm{K}_{2} \mathrm{CO}_{3}(0.1 \mathrm{M})$ followed by drying over $\mathrm{Na}_{2} \mathrm{SO}_{4}$. The solution was concentrated in vacuo and added dropwise to cold $\mathrm{MeOH}$. The precipitate was filtered off, washed with cold $\mathrm{MeOH}$ and dried in vacuo.

Yield: $0.569 \mathrm{~g}(67 \%)$, colorless powder; $\mathrm{DS}_{\mathrm{NB}}$ (determined from ${ }^{1} \mathrm{H}-\mathrm{NMR}$ spectrum of NC in $\mathrm{CDCl}_{3}$, Figure 3) 2.85; FT-IR (ATR) [ $\left.\mathrm{cm}^{-1}\right] 3061\left(v_{=\mathrm{C}-\mathrm{H}}\right) ; 2972,2947,2872\left(v_{-\mathrm{C}-\mathrm{H}}\right)$; $1736\left(v_{-\mathrm{C}=0}\right) ; 1571\left(v_{-\mathrm{C}=\mathrm{C}}\right) ; 1447\left(\delta_{-\mathrm{C}-\mathrm{H}}\right) ; 1335\left(\delta_{-\mathrm{CH} 3}\right) ; 1296 ; 1270 ; 1234,1151,1108,1063$ $\left(v_{\mathrm{C}-\mathrm{O}-\mathrm{C}}\right) ; 951 ; 906 ; 836 ; 775 ; 711\left(v_{=\mathrm{C}-\mathrm{H}}\right) ; 610 ; 500 ; 462 ;{ }^{1} \mathrm{H}-\mathrm{NMR}\left(300 \mathrm{MHz}, 298 \mathrm{~K}, \mathrm{CDCl}_{3}\right)$ : $\delta[\mathrm{ppm}]=6.43-5.55\left(\mathrm{~N} 5_{\text {endo/exo }}, \mathrm{N6}_{\text {endo/exo }}\right), 5.09$ (C5), 4.68 (C3), 4.42 (C1, C6a), 4.05 (C6b), 3.61 (C2, C4), 3.30-2.66 ( $\left.\mathrm{N1}_{\text {endo/exo, }} \mathrm{N} 2_{\text {endo }}, \mathrm{N} 4_{\text {endo/exo }}\right), 2.40-2.05$ ( $\left.\mathrm{N} 2_{\text {exo }}\right), 2.05$

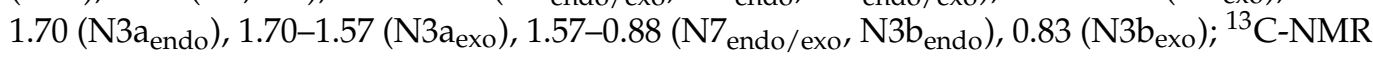
$\left(75 \mathrm{MHz}, 298 \mathrm{~K}, \mathrm{CDCl}_{3}\right): \delta$ [ppm] = 174.1-172.6 (E), 138.3-132.5 (N5, N6), 100.2 (C1), 75.7

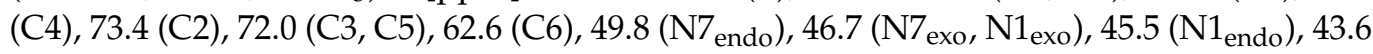
$\left(\mathrm{N} 2_{\text {exo }}\right), 43.3$ ( $\left(2_{\text {endo }}\right), 42.7\left(\mathrm{~N}_{\text {endo }}\right), 41.8\left(\mathrm{~N}_{\text {exo }}\right), 30.6\left(\mathrm{~N} 3_{\text {exo }}\right), 29.9\left(\mathrm{~N}_{\text {endo }}\right)$; elemental analysis (CHN) [\%] $66.52 \mathrm{C}, 6.29 \mathrm{H} . \delta$

\subsubsection{Synthesis of pyPz-NC via iEDDA}

NC (36.4 mg, $0.071 \mathrm{mmol}$, DS 2.85) was dissolved in THF and a solution of pyTz (20.2 mg, $0.0784 \mathrm{~mol}, 1.2 \mathrm{eq} / \mathrm{AGU}$ ) in THF was added quickly. The reaction was stirred at room temperature overnight. A change of color from pink to orange after $4 \mathrm{~h}$ and bright yellow overnight was observed characteristic for the conversion of the tetrazine. The solution was concentrated and added dropwise to cold $\mathrm{MeOH}$. The yellowish precipitate was filtered off, washed with cold $\mathrm{MeOH}$ and dried under vacuo.

Yield: $29.9 \mathrm{mg}(59 \%)$, yellowish solid, $\mathrm{DS}_{\mathrm{pyPz}}$ (determined from elemental analysis) 0.75; FT-IR (ATR) [cm $\left.{ }^{-1}\right] 3360\left(v_{\mathrm{N}-\mathrm{H}}\right) ; 3058\left(v_{=\mathrm{C}-\mathrm{H}}\right), 2970\left(v_{-\mathrm{C}-\mathrm{H}}\right) ; 1740\left(v_{-\mathrm{C}=0}\right) ; 1589,1564$, 1467,1428 ( $\left.v_{2-\text { monosubstituted pyridine }}\right) ; 1336\left(\delta_{-\mathrm{CH}}\right) ; 1271,1152,1030$ ( $\left.v_{\mathrm{C}-\mathrm{O}-\mathrm{C}}\right) ; 783 ; 746 ; 665$; 620; elemental analysis (CHN) [\%] 66.20 C, $5.76 \mathrm{H}, 5.93 \mathrm{~N}$.

\subsection{Determination of the Rate Constant of the iEDDA Reaction}

The rate constants $k$ of the iEDDA reaction of NC and NM with pyTz were measured using pseudo first order conditions (constant tetrazine concentration and excess of norbornene) using UV-Vis spectroscopy [28].

Stock solutions of NC (14.0 mM, DS 2.85, i.e., $40.0 \mathrm{mM}$ norbornene double bond), NM $(40.0 \mathrm{mM})$ and pyTz $(2.0 \mathrm{mM})$ were prepared in THF. For each experiment, the solutions were mixed in the order NC/NM, THF, pyTz in a quartz cuvette (Table 2) and immediately inserted into a UV-Vis spectrometer. The final concentration of pyTz was $1.0 \mathrm{mM}$ and of norbornene double bonds 5.0, 10.0 and $15.0 \mathrm{mM}$, corresponding to 5-15-fold excess. The decay of the absorption of pyTz at $542 \mathrm{~nm}$ was recorded $(1 \mathrm{~Hz}, 5 \mathrm{~min})$ and the experiments were repeated three times.

Table 2. Mixing formula for alkene:Tz ratios 5:1, 10:1 and 15:1.

\begin{tabular}{cccc}
\hline Alkene:Tz & NC/ NM $(\mu \mathrm{L})$ & THF $(\mu \mathrm{L})$ & pyTz $(\mu \mathrm{L})$ \\
\hline $5: 1$ & 250 & 750 & 1000 \\
$10: 1$ & 500 & 500 & 1000 \\
$15: 1$ & 750 & 250 & 1000 \\
\hline
\end{tabular}




\subsection{Measurements}

\subsubsection{NMR Spectroscopy}

NMR measurements were performed on a Bruker Avance 300 NMR (Billerica, MA, USA) spectrometer. Deuterated solvents were obtained from Cambridge Isotope Laboratories Inc. (Tewksbury, MA, USA) and remaining peaks were referenced according to literature [32]. Peak shapes are specified as follows: bs (broad singlet) and m (multiplet).

\subsubsection{Infrared Spectroscopy (ATR-FTIR)}

IR spectra were attained by an Alpha FT-IR spectrometer (Bruker; Billerica, MA, USA) using an attenuated total reflection (ATR) attachment. Spectra were obtained in a scan range between 4000 and $400 \mathrm{~cm}^{-1}$ with 48 scans and a resolution of $4 \mathrm{~cm}^{-1}$. The data was analyzed by Bruker's OPUS 4.0 software (Bruker; Billerica, MA, USA).

\subsubsection{Elemental Analysis}

The mass fractions of carbon, hydrogen and nitrogen were determined with a Vario EL III Element Analyzer from Elementar GmbH. (Langenselbold, Germany). The degree of substitution for the clicked products was calculated according to adapted equations from literature [33].

\subsubsection{UV/Vis Spectroscopy}

Absorption spectra were recorded on a Shimadzu spectrophotometer UV-1800. (Kyoto, Japan) The emission was measured on a Hitachi F-7000 fluorescence spectrometer (Tokyo, Japan) equipped with a red-sensitive photomultiplier R928 from Hamamatsu (Hamatsu, Japan).

\section{Conclusions}

In summary, simultaneous desilylation-esterification of trimethylsilyl cellulose was proven to be a highly efficient way to obtain norbornylated cellulose with a DS $>2.8$. The highly substituted NC derivative was subjected to inverse electron-demand Diels-Alder "click" chemistry with 3,6-di(pyridin-2-yl)-1,2,4,5-tetrazine. It turns out that the observed reaction kinetics are competitive with CuAAC while being copper and catalyst free. This procedure could be the starting point for many other reactions involving polysaccharide esters and tetrazines since the presented approach is generic and applicable to many other substrates. Since copper is avoided in this "click" reaction, compounds intended for medical use are a major field where this reaction type could find a large application area [22]. Still, more efforts need to be performed to fully elucidate the structure and substitution patterns of the clicked product. This could be accomplished using solid state ${ }^{13} \mathrm{C}$-NMR spectroscopy and/or isotope labeling $\left({ }^{13} \mathrm{C},{ }^{15} \mathrm{~N}\right)$ of the tetrazine component.

$\mathrm{NC}$ itself is a potentially interesting component for chemical transformations such as grafting-from polymerization using ring-opening metathesis polymerization (ROMP) [34] which opens up a manifold of possibilities to prepare biocomposites, and hybrid materials $[35,36]$. As opposed to previous endeavors [37], the aforementioned good organosolubility of NC as presented herein enables a true grafting-from approach which could be utilized e.g., for the preparation of bottlebrush copolymers.

Author Contributions: C.W. formal analysis, A.-C.K.; investigation, V.S., A.-C.K.; resources, A.-C.K.; data curation, C.W., V.S.; writing—original draft preparation, S.S., A.-C.K., C.S.; writing-review and editing, C.S., S.S.; visualization, A.-C.K.; supervision, A.-C.K., C.S.; funding acquisition, A.-C.K. All authors have read and agreed to the published version of the manuscript.

Funding: Funding by the Austrian Science Fund (FWF) [T 578-N19] is gratefully acknowledged.

Institutional Review Board Statement: Not applicable.

Informed Consent Statement: Not applicable.

Data Availability Statement: Data is contained within the article. 
Acknowledgments: Open Access Funding by the Graz University of Technology is gratefully acknowledged.

Conflicts of Interest: The authors declare no conflict of interest.

Sample Availability: Samples of the compounds are available from the authors.

\section{Appendix A}

Appendix A.1. Characterization Data for NC

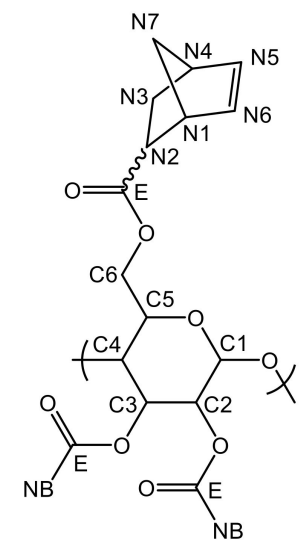

DS (from ${ }^{1} \mathrm{H}-\mathrm{NMR}$ spectrum of $\mathrm{NC}$ in $\mathrm{CDCl}_{3}$, Figure 1): 2.85 .

${ }^{1} \mathrm{H}-\mathrm{NMR}\left(300 \mathrm{MHz}, 298 \mathrm{~K}, \mathrm{CDCl}_{3}\right): \delta[\mathrm{ppm}]=6.43-5.55\left(\mathrm{~m}, 5.69 \mathrm{H}, \mathrm{N} 5\right.$ endo/exo, $\left.\mathrm{N}_{\text {endo/exo }}\right)$, 5.09 (bs, 1.04 H, C5), 4.68 (bs, 1.15 H, C3), 4.42 (bs, 1.69 H, C1, C6a), 4.05 (bs, 1.05 H, C6b), 3.61 (bs, 2.06 H, C2, C4), 3.30-2.66 (m, 8.04 H, N1 endo/exo, $_{\text {N2 }}$ endo, N4 endo/exo $_{\text {end }}$ 2.40-2.05 ( $\mathrm{m}, 0.77 \mathrm{H}, \mathrm{N} 2$ exo $_{\text {) }}$, 2.05-1.70 (m, 2.83 H, N3a $\left.\mathrm{a}_{\text {endo }}\right), 1.70-1.57$ (m, 0.70 H, N3a exo $), 1.57-0.88$ (m, $8.15 \mathrm{H}, \mathrm{N} 7$ endo/exo, $\mathrm{N} 3 \mathrm{~b}_{\text {endo }}$ ), 0.83 (m, $\left.0.11 \mathrm{H}, \mathrm{N} 3 \mathrm{~b}_{\text {exo }}\right), 0.06$ (s, $\left.0.05 \mathrm{H}, \mathrm{TMS}\right)$.

${ }^{13} \mathrm{C}-\mathrm{NMR}\left(75 \mathrm{MHz}, 298 \mathrm{~K}, \mathrm{CDCl}_{3}\right): \delta$ [ppm] = 174.1-172.6 (C $\left.\mathrm{q}, \mathrm{E}\right), 138.3-132.5(\mathrm{~N} 5, \mathrm{~N} 6), 100.2$ (C1), 75.7 (C4), 73.4 (C2), 72.0 (C3, C5), 62.6 (C6), 49.8 (N7 endo), 46.7 (N7 exo $\left._{\text {ex }} \mathrm{N}_{\text {exo }}\right), 45.5$ $\left(\mathrm{N} 1_{\text {endo }}\right), 43.6$ (N2 exo $), 43.3$ (N2 endo $), 42.7$ (N4 endo $), 41.8\left(\mathrm{~N} 4_{\text {exo }}\right), 30.6\left(\mathrm{~N} 3_{\text {exo }}\right), 29.9$ (N3 endo $)$.

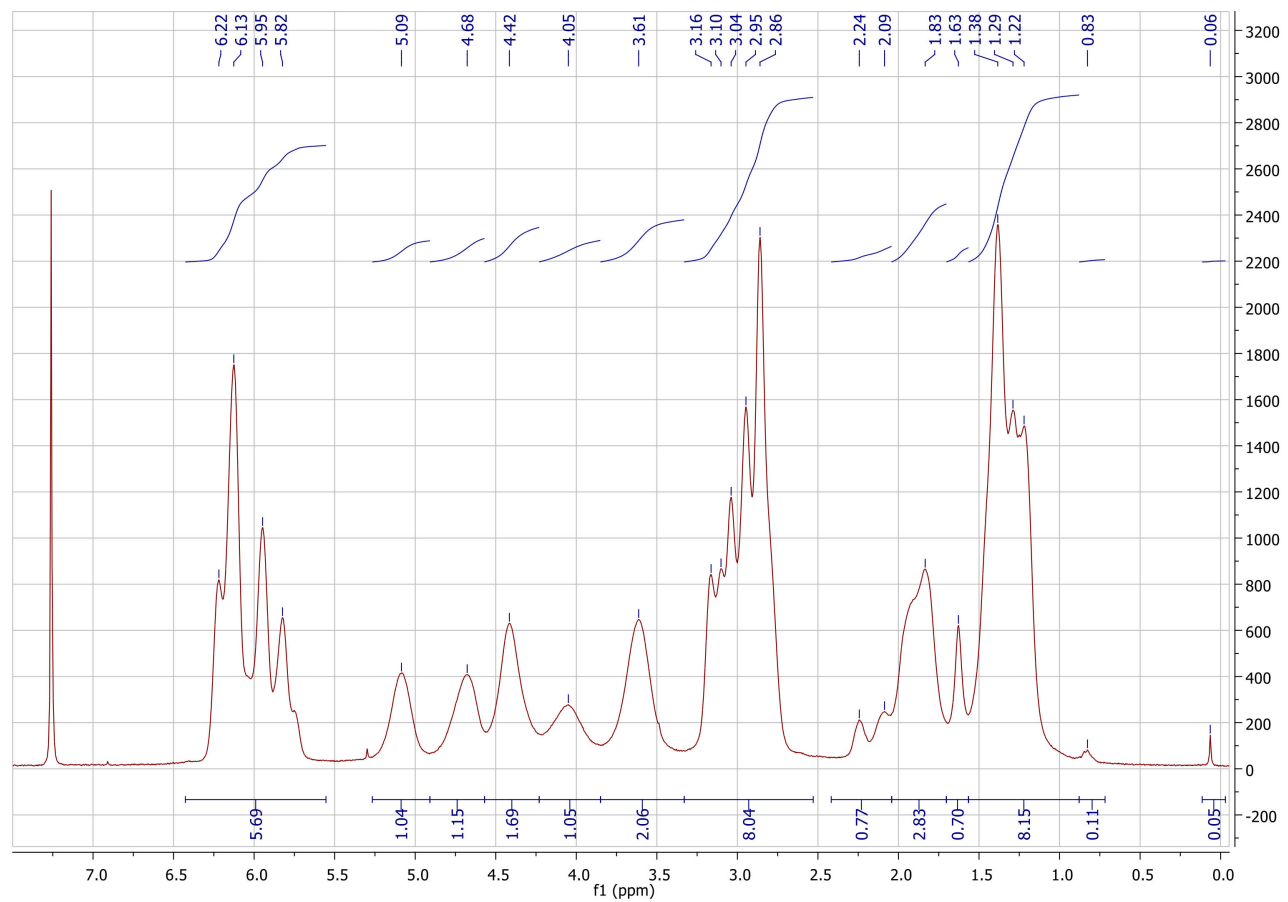

Figure A1. ${ }^{1} \mathrm{H}-\mathrm{NMR}$ spectrum of $\mathrm{NC}$ in $\mathrm{CDCl}_{3}$ at $298 \mathrm{~K}$. 


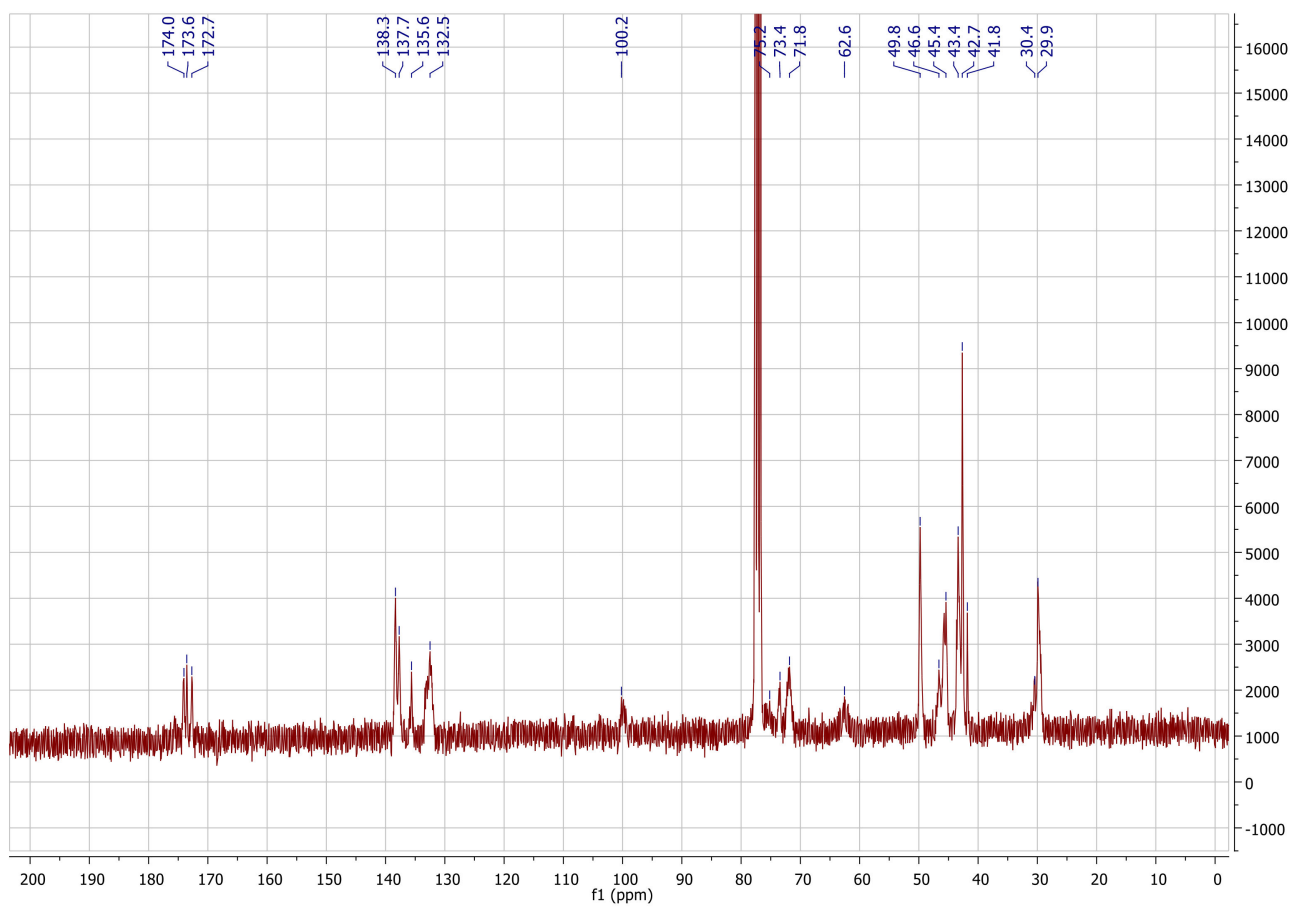

Figure A2. ${ }^{13} \mathrm{C}$-NMR spectrum of $\mathrm{NC}$ in $\mathrm{CDCl}_{3}$ at $298 \mathrm{~K}$.

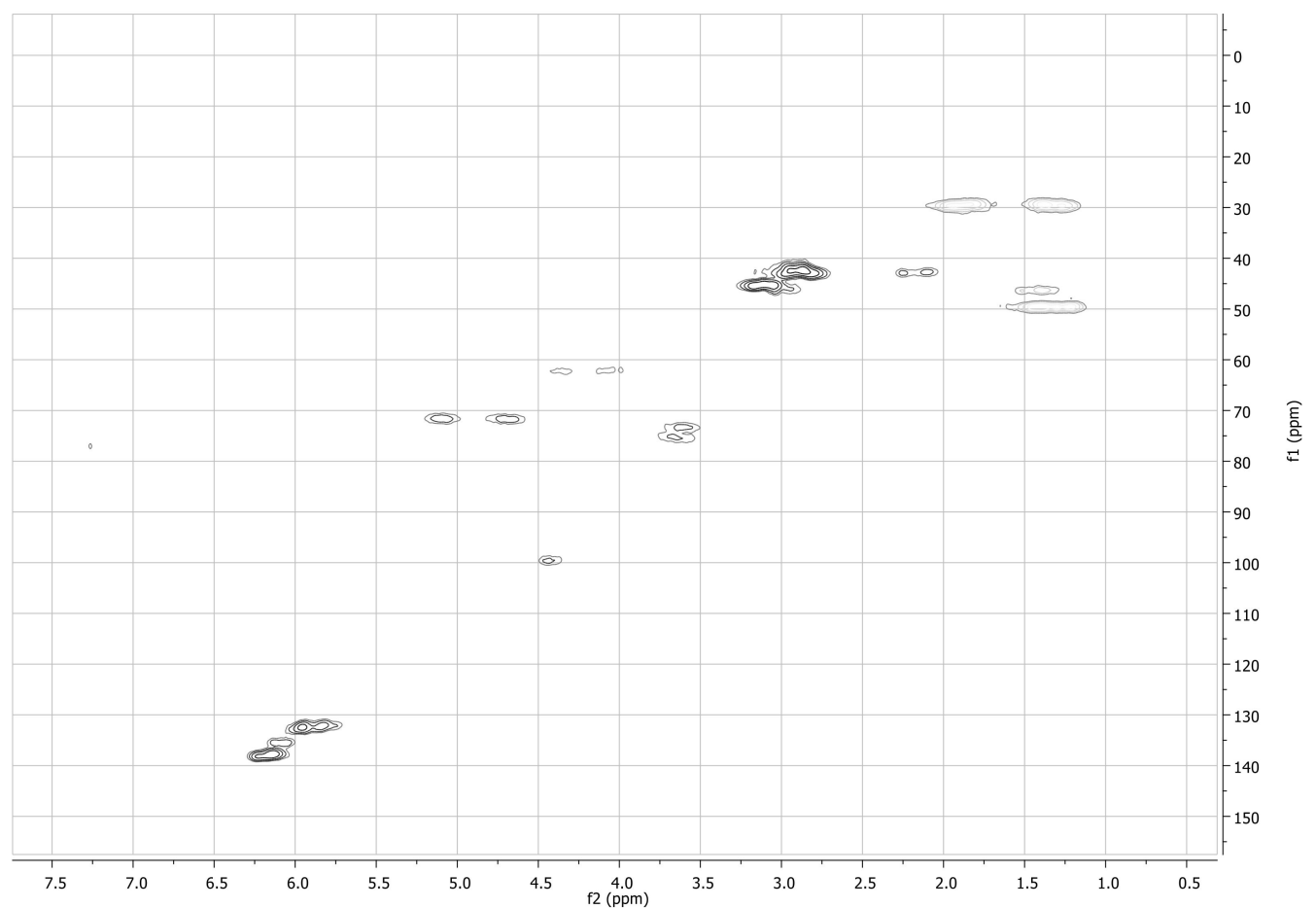

Figure A3. ${ }^{13} \mathrm{C}-{ }^{1} \mathrm{H}-\mathrm{HSQC}$ NMR spectrum of $\mathrm{NC}$ in $\mathrm{CDCl}_{3}$ at $298 \mathrm{~K}$.

FT-IR (ATR) [cm $\left.{ }^{-1}\right]$ ]: $3061\left(v_{=\mathrm{C}-\mathrm{H}}\right) ; 2972,2947,2872\left(v_{-\mathrm{C}-\mathrm{H}}\right) ; 1736\left(v_{-\mathrm{C}=0}\right) ; 1571\left(v_{-\mathrm{C}=\mathrm{C}}\right) ; 1447$ $\left(\delta_{-\mathrm{C}-\mathrm{H}}\right) ; 1335\left(\delta_{-\mathrm{CH} 3}\right) ; 1296 ; 1270 ; 1234,1151,1108,1063$ ( $\left.v_{\mathrm{C}-\mathrm{O}-\mathrm{C}}\right) ; 951 ; 906 ; 836 ; 775 ; 711$ $\left(v_{=\mathrm{C}-\mathrm{H}}\right) ; 610 ; 500 ; 462$.

Elemental analysis (CHN) [\%]: $66.52 \mathrm{C}, 6.29 \mathrm{H}$ (measured); $66.52 \mathrm{C}, 6.69 \mathrm{H}$, (calculated with 5 water molecules, NC DS 2.85). 
Appendix A.2. Characterization of pyPz-NC

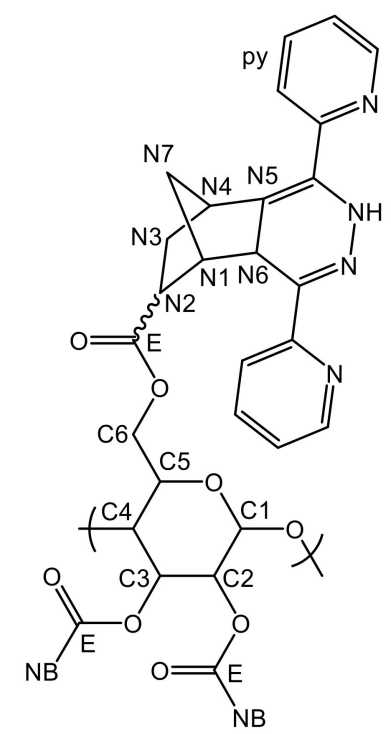

DS (from elemental analysis): 0.75 .

${ }^{1}$ H-NMR $\left(300 \mathrm{MHz}, 298 \mathrm{~K}, \mathrm{CDCl}_{3}\right): \delta[\mathrm{ppm}]=8.98-7.29(\mathrm{~m}, 5.59 \mathrm{H}, \mathrm{py}), 6.43-5.55(\mathrm{~m}, 4.15 \mathrm{H}$, $\mathrm{N5}_{\text {endo/exo, }} \mathrm{N6}_{\text {endo/exo }}$ ), 5.09-4.05 (m, $\left.5.08 \mathrm{H}, \mathrm{C} 5, \mathrm{C} 3, \mathrm{C} 1, \mathrm{C} 6\right), 3.85-3.33$ (m, $2.55 \mathrm{H}, \mathrm{C} 2, \mathrm{C} 4$, $\mathrm{MeOH}), 3.30-2.21\left(\mathrm{~m}, 8.00 \mathrm{H}, \mathrm{N} 1_{\text {endo/exo }}, \mathrm{N}_{\text {endo/exo, }} \mathrm{N} 4_{\text {endo/exo }}\right), 2.40-2.15-1.70(\mathrm{~m}, 2.69 \mathrm{H}$,

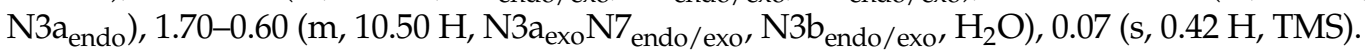

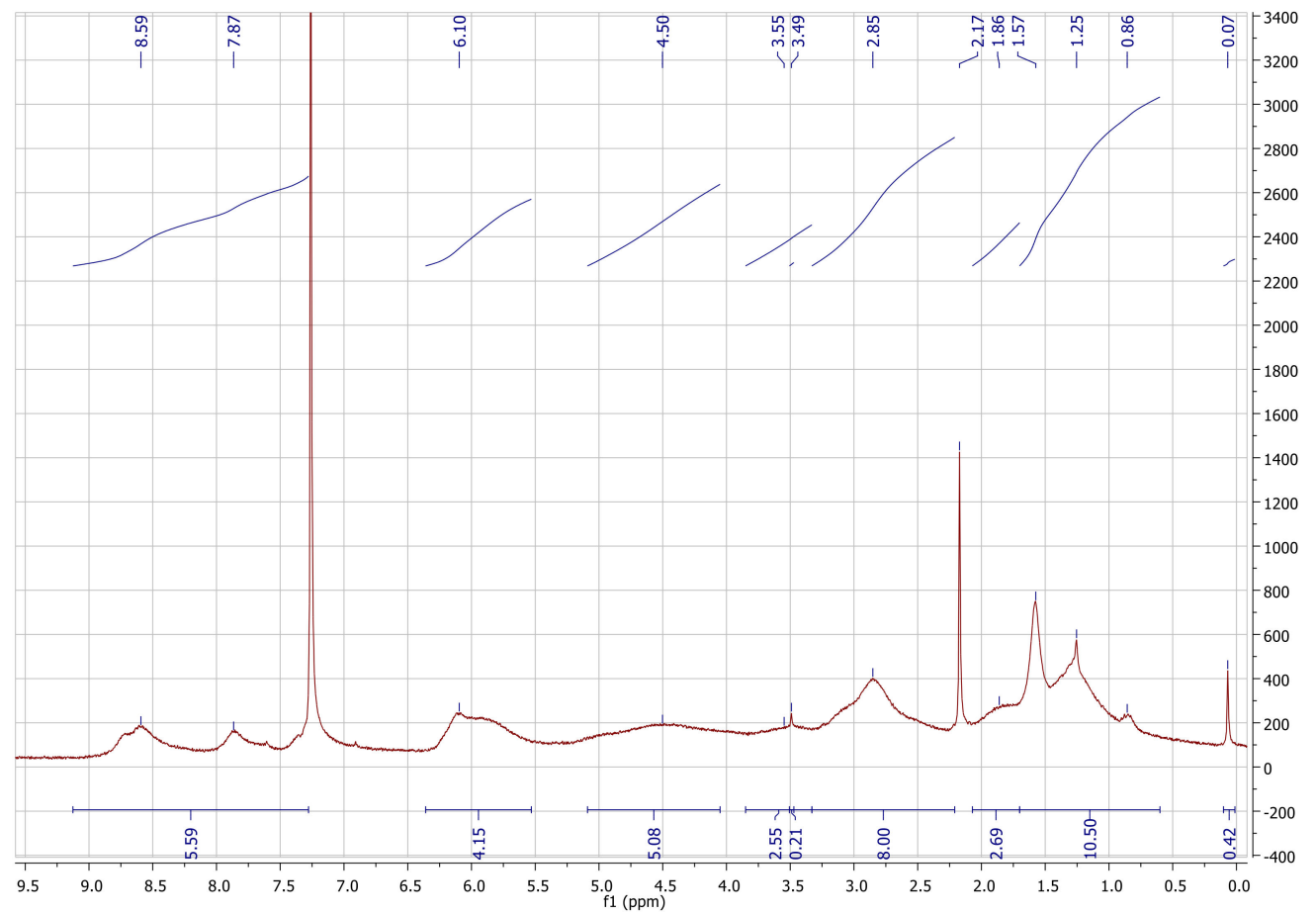

Figure A4. ${ }^{1} \mathrm{H}-\mathrm{NMR}$ spectrum of pyPz-NC in $\mathrm{CDCl}_{3}$ at $298 \mathrm{~K}$.

FT-IR (ATR) $\left[\mathrm{cm}^{-1}\right]$ ]: $3360\left(v_{\mathrm{N}-\mathrm{H}}\right) ; 3058\left(v_{=\mathrm{C}-\mathrm{H}}\right), 2970\left(v_{-\mathrm{C}-\mathrm{H}}\right) ; 1740\left(v_{-\mathrm{C}=0}\right) ; 1589,1564,1467$,

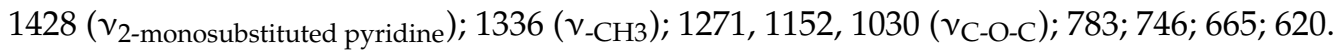
Elemental analysis (CHN) [\%]: 66.20 C, $5.76 \mathrm{H}, 5.93 \mathrm{~N}$ (measured); $67.09 \mathrm{C}, 6.09 \mathrm{H}, 5.69 \mathrm{~N}$ (calculated with 5 water molecules, NC DS 2.85, pyPz DS 0.75). 


\section{References}

1. Kolb, H.C.; Finn, M.G.; Sharpless, K.B. Click Chemistry: Diverse Chemical Function from a Few Good Reactions. Angew. Chem. Int. Ed. 2001, 40, 2004-2021. [CrossRef]

2. Moses, J.E.; Moorhouse, A.D. The growing applications of click chemistry. Chem. Soc. Rev. 2007, 36, 1249-1262. [CrossRef]

3. Liang, L.; Astruc, D. The copper(I)-catalyzed alkyne-azide cycloaddition (CuAAC) "click" reaction and its applications. An overview. Coord. Chem. Rev. 2011, 255, 2933-2945. [CrossRef]

4. Navarro, J.R.G.; Conzatti, G.; Yu, Y.; Fall, A.B.; Mathew, R.; Edén, M.; Bergström, L. Multicolor Fluorescent Labeling of Cellulose Nanofibrils by Click Chemistry. Biomacromolecules 2015, 16, 1293-1300. [CrossRef] [PubMed]

5. Orelma, H.; Johansson, L.-S.; Filpponen, I.; Rojas, O.J.; Laine, J. Generic Method for Attaching Biomolecules via Avidin-Biotin Complexes Immobilized on Films of Regenerated and Nanofibrillar Cellulose. Biomacromolecules 2012, 13, 2802-2810. [CrossRef] [PubMed]

6. Filpponen, I.; Kontturi, E.; Nummelin, S.; Rosilo, H.; Kolehmainen, E.; Ikkala, O.; Laine, J. Generic Method for Modular Surface Modification of Cellulosic Materials in Aqueous Medium by Sequential "Click" Reaction and Adsorption. Biomacromolecules 2012, 13, 736-742. [CrossRef]

7. Koschella, A.; Hartlieb, M.; Heinze, T. A “click-chemistry" approach to cellulose-based hydrogels. Carbohydr. Polym. 2011, 86, 154-161. [CrossRef]

8. Koschella, A.; Richter, M.; Heinze, T. Novel cellulose-based polyelectrolytes synthesized via the click reaction. Carbohydr. Res. 2010, 345, 1028-1033. [CrossRef]

9. Chen, J.; Lin, N.; Huang, J.; Dufresne, A. Highly alkynyl-functionalization of cellulose nanocrystals and advanced nanocomposites thereof via click chemistry. Polym. Chem. 2015, 6, 4385-4395. [CrossRef]

10. Montañez, M.I.; Hed, Y.; Utsel, S.; Ropponen, J.; Malmström, E.; Wågberg, L.; Hult, A.; Malkoch, M. Bifunctional Dendronized Cellulose Surfaces as Biosensors. Biomacromolecules 2011, 12, 2114-2125. [CrossRef] [PubMed]

11. Copper: Health Information Summary, Environmental Fact Sheet, ARD-EHP-9 New Hampshire Department of Environmental Services. 2005. Available online: http://des.nh.gov/organization/commissioner/pip/factsheets/ard/documents/ard-ehp-9.pdf (accessed on 3 March 2021).

12. Eskici, G.; Axelsen, P.H. Copper and Oxidative Stress in the Pathogenesis of Alzheimer's Disease. Biochem. 2012, 51, 6289-6311. [CrossRef] [PubMed]

13. Codelli, J.A.; Baskin, J.M.; Agard, N.J.; Bertozzi, C.R. Second-Generation Difluorinated Cyclooctynes for Copper-Free Click Chemistry. J. Am. Chem. Soc. 2008, 130, 11486-11493. [CrossRef] [PubMed]

14. Sletten, E.M.; Bertozzi, C.R. A Hydrophilic Azacyclooctyne for Cu-Free Click Chemistry. Org. Lett. 2008, 10, 3097-3099. [CrossRef]

15. Baskin, J.M.; Prescher, J.A.; Laughlin, S.T.; Agard, N.J.; Chang, P.V.; Miller, I.A.; Lo, A.; Codelli, J.A.; Bertozzi, C.R. Copper-free click chemistry for dynamic in vivo imaging. Proc. Natl. Acad. Sci. 2007, 104, 16793-16797. [CrossRef]

16. Agard, N.J.; Prescher, J.A.; Bertozzi, C.R. A Strain-Promoted [3 + 2] Azide-Alkyne Cycloaddition for Covalent Modification of Biomolecules in Living Systems. J. Am. Chem. Soc. 2004, 126, 15046-15047. [CrossRef]

17. Ning, X.; Guo, J.; Wolfert, M.A.; Boons, G.-J. Visualizing Metabolically Labeled Glycoconjugates of Living Cells by Copper-Free and Fast Huisgen Cycloadditions. Angew. Chem. Int. Ed. 2008, 47, 2253-2255. [CrossRef]

18. Blackman, M.L.; Royzen, M.; Fox, J.M. Tetrazine Ligation: Fast Bioconjugation Based on Inverse-Electron-Demand Diels-Alder Reactivity. J. Am. Chem. Soc. 2008, 130, 13518-13519. [CrossRef] [PubMed]

19. Knall, A.-C.; Hollauf, M.; Saf, R.; Slugovc, C. A trifunctional linker suitable for conducting three orthogonal click chemistries in one pot. Org. Biomol. Chem. 2016, 14, 10576-10580. [CrossRef]

20. Wu, H.; Devaraj, N.K. Advances in Tetrazine Bioorthogonal Chemistry Driven by the Synthesis of Novel Tetrazines and Dienophiles. Accounts Chem. Res. 2018, 51, 1249-1259. [CrossRef] [PubMed]

21. Knall, A.-C.; Kovačič, S.; Hollauf, M.; Reishofer, D.; Saf, R.; Slugovc, C. Inverse electron demand Diels-Alder (iEDDA) functionalisation of macroporous poly(dicyclopentadiene) foams. Chem. Commun. 2013, 49, 7325-7327. [CrossRef] [PubMed]

22. Devaraj, N.K.; Weissleder, R. Biomedical Applications of Tetrazine Cycloadditions. Accounts Chem. Res. 2011, 44, 816-827. [CrossRef]

23. Knall, A.-C.; Slugovc, C. Inverse electron demand Diels-Alder (iEDDA)-initiated conjugation: A (high) potential click chemistry scheme. Chem. Soc. Rev. 2013, 42, 5131-5142. [CrossRef]

24. Meng, X.; Edgar, K.J. “Click” reactions in polysaccharide modification. Prog. Polym. Sci. 2016, 53, 52-85. [CrossRef]

25. Fox, S.C.; Li, B.; Xu, D.; Edgar, K.J. Regioselective Esterification and Etherification of Cellulose: A Review. Biomacromolecules 2011, 12, 1956-1972. [CrossRef]

26. Stein, A.; Klemm, D. Syntheses of cellulose derivatives via O-triorganosilyl celluloses, 1 . Effective synthesis of organic cellulose esters by acylation of trimethylsilyl celluloses. Die Makromol. Chem. Rapid Commun. 1988, 9, 569-573. [CrossRef]

27. Kono, H.; Hashimoto, H.; Shimizu, Y. NMR characterization of cellulose acetate: Chemical shift assignments, substituent effects, and chemical shift additivity. Carbohydr. Polym. 2015, 118, 91-100. [CrossRef]

28. Knall, A.-C.; Hollauf, M.; Slugovc, C. Kinetic studies of inverse electron demand Diels-Alder reactions (iEDDA) of norbornenes and 3,6-dipyridin-2-yl-1,2,4,5-tetrazine. Tetrahedron Lett. 2014, 55, 4763-4766. [CrossRef] 
29. Bakkali, H.; Marie, C.; Ly, A.; Thobie-Gautier, C.; Graton, J.; Pipelier, M.; Sengmany, S.; Léonel, E.; Nédélec, J.-Y.; Evain, M.; et al. Functionalized 2,5-Dipyridinylpyrroles by Electrochemical Reduction of 3,6-Dipyridinylpyridazine Precursors. Eur. J. Org. Chem. 2008, 2008, 2156-2166. [CrossRef]

30. Bruson, H.A. The Chemistry of Acrylonitrile. I. Cyanoethylation of Active Methylene Groups. J. Am. Chem. Soc. 1942, 64, 2457-2461. [CrossRef]

31. Xia, Y.; LaRock, R.C. Castor oil-based thermosets with varied crosslink densities prepared by ring-opening metathesis polymerization (ROMP). Polym. 2010, 51, 2508-2514. [CrossRef]

32. Gottlieb, H.E.; Kotlyar, V.; Nudelman, A. NMR Chemical Shifts of Common Laboratory Solvents as Trace Impurities. J. Org. Chem. 1997, 62, 7512-7515. [CrossRef] [PubMed]

33. Bendoraitiene, J.; Kavaliauskaite, R.; Klimaviciute, R.; Zemaitaitis, A. Peculiarities of Starch Cationization with Glycidyltrimethylammonium Chloride. Starch Stärke 2006, 58, 623-631. [CrossRef]

34. Leitgeb, A.; Wappel, J.; Slugovc, C. The ROMP toolbox upgraded. Polym. 2010, 51, 2927-2946. [CrossRef]

35. Meng, X.; Matson, J.B.; Edgar, K.J. Olefin cross-metathesis, a mild, modular approach to functionalized cellulose esters. Polym. Chem. 2014, 5, 7021-7033. [CrossRef]

36. Meng, X.; Edgar, K.J. Synthesis of amide-functionalized cellulose esters by olefin cross-metathesis. Carbohydr. Polym. 2015, 132, 565-573. [CrossRef] [PubMed]

37. Carlsson, L.; Malmström, E.; Carlmark, A. Surface-initiated ring-opening metathesis polymerisation from cellulose fibres. Polym. Chem. 2012, 3, 727-733. [CrossRef] 